\title{
Continuous Lighting Reduces Conidial Production and Germinability in the Rose Powdery Mildew Pathosystem
}

\author{
A. Suthaparan, Department of Plant and Environmental Sciences, Norwegian University of Life Sciences, 1432 Ås, \\ Norway; Arne Stensvand, Department of Plant and Environmental Sciences, Norwegian University of Life Sci- \\ ences, and Norwegian Institute for Agricultural and Environmental Research, Høgskoleveien 7, 1432 Ås, Norway; \\ S. Torre, Department of Plant and Environmental Sciences, Norwegian University of Life Sciences; Maria L. \\ Herrero, Norwegian Institute for Agricultural and Environmental Research, Ås; R. I. Pettersen, Department of \\ Plant and Environmental Sciences, Norwegian University of Life Sciences; David M. Gadoury, Department of Plant \\ Pathology and Plant-Microbe Biology, Cornell University, New York State Agricultural Experiment Station, Geneva \\ 14456; and Hans Ragner Gislerød, Department of Plant and Environmental Sciences, Norwegian University of Life \\ Sciences
}

\begin{abstract}
Suthaparan, A., Stensvand, A., Torre, S., Herrero, M. L., Pettersen, R. I., Gadoury, D. M., and Gislerød, H. R. 2010. Continuous lighting reduces conidial production and germinability in the rose powdery mildew pathosystem. Plant Dis. 94:339-344.

The effect of day length on production and germinability of conidia and severity of disease caused by Podosphaera pannosa, the causal agent of rose powdery mildew, was studied. Whole potted plants or detached leaves of Rosa interspecific hybrid 'Mistral' were inoculated with $P$. pannosa and exposed to $0,12,18,20,22$, or $24 \mathrm{~h}$ of artificial light per day in growth chambers equipped with mercury lamps. Increasing duration of illumination from 18 to 20 to $24 \mathrm{~h}$ per day reduced production of conidia by 22 to $62 \%$. Exposure to $24 \mathrm{~h}$ of illumination per day also strongly reduced disease severity compared with $18 \mathrm{~h}$. Our results suggest that increasing day lengths from $18 \mathrm{~h}$ per day to 20 to $24 \mathrm{~h}$ may suppress the disease significantly and, thereby, reduce the need for fungicide applications against powdery mildew.
\end{abstract}

Powdery mildew (Podosphaera pannosa (Wallr.) de Bary) is a widespread disease of roses that is particularly troublesome in greenhouse production of hybrid roses $($ Rosa $\times$ hybrida $)$. Although the pathogen rarely kills the plant, infection reduces host plant vigor, productivity, and esthetic (and therefore economic) value. In greenhouses, the pathogen is disseminated as conidia produced primarily on diseased leaves. The ascigerous stage of the pathogen has no known role in the epidemiology of the disease in greenhouse rose production.

In general, relatively cool atmospheric conditions with moderate temperature and reduced light (shade) are favorable to powdery mildews $(28,29)$. In $P$. pannosa, colony growth and conidial germination occur at $50 \%$ relative humidity (RH) (22) and optimum $\mathrm{RH}$ for conidia germination is nearly $100 \%$ (10). Furthermore, germination is reduced by free water (24) and temperatures above $30^{\circ} \mathrm{C}(21)$. Dissemination of conidia, as inferred from spore trapping, was associated with rising tem-

Corresponding author: D. M. Gadoury

E-mail: dmg4@nysaes.cornell.edu

Accepted for publication 23 November 2009.

doi:10.1094/PDIS-94-3-0339

(C) 2010 The American Phytopathological Society perature, increasing solar radiation, and decreasing RH (1).

The influence of light on biological activity of fungi has been extensively studied in Aspergillus nidulans (3) and Neurospora crassa $(2,27)$. However, little is known about the effect of light on P. pannosa. Importance of supplemental lighting in rose cultivation is well established, and there is an increase in productivity with increasing light intensity and day length $(4,11,14,16,25)$. The use of supplementary lighting is essential for year-round rose production in Norway due to low natural irradiance during the winter (12). Our preliminary studies indicated that severity of powdery mildew was reduced on roses grown under continuous lighting compared with day lengths of 16 to $18 \mathrm{~h}(15,17)$. Our objectives in the present study were to (i) investigate the effect of day length on germination, formation, and productivity of conidia by P. pannosa; and (ii) quantify the effect of supplemental lighting on severity of rose powdery mildew. Preliminary accounts of this work have been published $(17,20,26)$.

\section{MATERIALS AND METHODS}

Production of host plant material. Mildew-free potted miniature rose plants (Rosa $\times$ hybrida 'Mistral') were grown in limed and fertilized peat (Floralux; Nittedal torv industri $\mathrm{A} / \mathrm{S}$, Norway) and perlite
(25\% by volume) in a greenhouse compartment to produce plant material for the experiments. Mercury lamps (Powerstar HQI-BT 400W/D day light; OSRAM $\mathrm{GmbH}$, Augsburg, Germany) at photon flux densities (PFDs) (400 to $700 \mathrm{~nm}$ ) of $200 \mu \mathrm{mol} \mathrm{m} \mathrm{m}^{-2} \mathrm{~s}^{-2} 1$ recorded at the top of the plants were used as a supplementary light source ( $18 \mathrm{~h}$ per day). The lights were automatically turned off when natural light exceeded $200 \mu \mathrm{mol} \mathrm{m} \mathrm{m}^{-2} \mathrm{~s}^{-1}$. Temperature was set at $20^{\circ} \mathrm{C}$ and $\mathrm{RH}$ at $80 \%$. Plants were exposed to evaporated sulfur for $4 \mathrm{~h}$ per day during the night and watered with complete nutrient solution when needed. The plants were pruned to induce young, active shoot growth to ensure sufficient supply of uniformly aged, mildew-free leaflets.

Production of inoculum. Rose leaves bearing powdery mildew colonies were obtained from a commercial greenhouse located in southeastern Norway. Detached young and newly unfolded rose leaflets from the abovementioned greenhouse compartment were surface sterilized by soaking them in sterile distilled water for 15 min followed by 4-min soaking in $0.5 \%$ sodium hypochlorite solution with Tween 20 (Sigma-Aldrich Chemie GmbH, Steinheim, Germany) at $30 \mu \mathrm{l} /$ liter followed by three rinses in sterile distilled water, each lasting 3 to $4 \mathrm{~min}$. This process also removed any sulfur residue. The leaflets were placed in petri dishes containing water agar (15 $\left.\mathrm{g} \mathrm{liter}^{-1}\right)$ and were inoculated by touching them gently with mildewed leaves from the commercial greenhouse. The petri dishes with the leaflets were sealed by Parafilm and kept in an incubator for 7 days with 16-h diurnal light periods provided by cool white florescent lamps (Philips, The Netherlands) at PFD (400 to $700 \mathrm{~nm}$ ) of $30 \mu \mathrm{mol} \mathrm{m} \mathrm{m}^{-2} \mathrm{~s}^{-1}$ at the top of the petri dish lids and $20 \pm 1{ }^{\circ} \mathrm{C}$.

These mildewed leaflets from the incubator were then used to inoculate another set of clean leaves by transferring single conidial chains. An eyelash attached to a fine glass needle was used to trap the single chain from diseased leaves, and a chain 
of conidia was deposited directly on the clean leaves under a stereomicroscope. The petri dishes were sealed and incubated for 7 days in the incubator with conditions as detailed before. Following incubation, described above to reduce the risk of contamination with other microorganisms.

Disease-free plants of Mistral were inoculated by gently touching them with mildewed, detached leaves kept in the incubator as described above. Inoculated plants were kept in an isolated growth chamber throughout the experimental period, with $18 \mathrm{~h}$ of diurnal lighting provided by mercury lamps of the same type as described above, at PFD of $200 \mu \mathrm{mol} \mathrm{m}{ }^{-2}$ $\mathrm{s}^{-1}, 20^{\circ} \mathrm{C}$ and $80 \% \mathrm{RH}$. The inoculum was renewed by continuous replacement of healthy plants in the growth chamber.

In all experiments (detached leaves or whole plant), inoculum from 7-day-old cultures was used. Seven days before each experiment, cleaned, detached leaves were placed in petri dishes containing water agar and sprayed with a conidial suspension. To obtain the suspension, 20 young mildewed leaflets from diseased plants in the growth chamber were added to a $50-\mathrm{ml}$ centrifuge tube containing $25 \mathrm{ml}$ of distilled water and shaken by hand for approximately $1 \mathrm{~min}$. Leaflets were removed from the centrifuge tube, and the conidial suspensions were sprayed onto cleaned, detached leaflets placed in petri dishes containing water agar with a hand-held sprayer (approximately $1 \mathrm{ml}$ per 20 leaflets). Petri dishes were sealed by Parafilm and kept in the incubator for 7 days under day-old cultures are hereafter called source inoculum.

Materials and equipment designed for experiments. Experiments were conducted both in vitro (detached leaves) and in vivo (whole plants) in growth chambers. Growth chamber lighting was with mercury lamps (same lamp type as described conidia were transferred two more times as conditions as described above. These 7-

above) with PFD of $50 \pm 5 \mu \mathrm{mol} \mathrm{m} \mathrm{m}^{-2} \mathrm{~s}^{-1}$ when lamps were on and temperature and $\mathrm{RH}$ were kept at $20 \pm 2^{\circ} \mathrm{C}$ and $80 \pm 5 \%$, respectively. Investigations with germination and formation of conidia were conducted with detached, clean leaves placed in double-room humidity boxes. Petri dishes $(90 \mathrm{~mm})$ were perforated with 20 circular holes (each with a diameter of 2 $\mathrm{mm}$ ) along the bottom edge of the dishes by using an electrical heater. The perforated petri dishes were glued on top of a 500-ml plastic container with the same diameter and made into double-room humidity boxes (hereafter called humidity boxes). The lower part (the plastic container) contained $100 \mathrm{ml}$ of a saturated $\mathrm{KCl}$ salt solution $(34 \mathrm{~g}$ in $100 \mathrm{ml}$ of distilled water) and, in the upper part (the petri dish), a layer of water agar (50 $\mathrm{mm}$ in diameter) was placed. The agar did not cover the holes, allowing air to flow between the two parts, thus ensuring a constant high humidity $(96 \pm 2 \% \mathrm{RH})$ in the upper part. Detached surface-sterilized and cleaned rose leaflets were placed with the abaxial side up on the agar layer.

For production of conidia (combination of formation and release) and disease severity experiments, whole plants of the same age, healthy, disease free, and with uniform canopies were selected from the greenhouse compartment mentioned above. For conidia productivity experiments, four wind tunnels were constructed (Fig. 1). An electric wind blower (Enermax UC-8FAB, China), 80 by 80 by $25 \mathrm{~mm}$, with manually adjustable speed control ( 1,000 to $3,000 \mathrm{rpm}$ ) fixed to the upwind end of the tunnel, drew ambient air into the tunnel. The intake air was drawn through a spongy synthetic air filter medium (FILTRAIR; Peregrine Industries Pvt. Ltd, Campbellfield, Victoria, Australia) of approximately $2 \mathrm{~cm}$ in thickness that ensured both laminar and cleaned air flow. The wind tunnel was composed of a lighttransmitting Plexiglas tube (main tube: 500

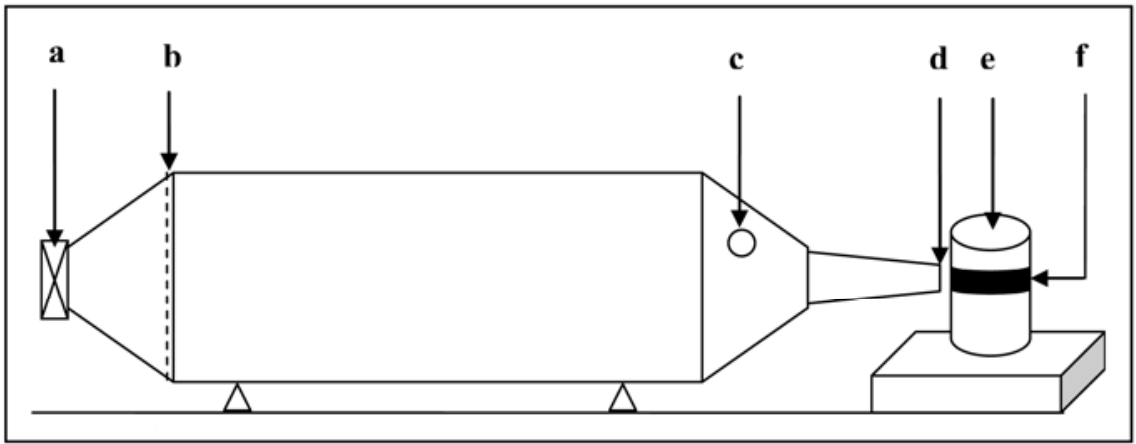

Fig. 1. Schematic illustration of a wind tunnel showing an electric wind blower with manually adjustable speed control (a); spongy filter (b); overflow orifice, $29 \mathrm{~mm}$ in diameter (c); nozzle orifice, 27 by $2 \mathrm{~mm}$ (d); clock cylinder (e); and microscope tape (f). Ambient air entered through the wind blower fixed inside the left plastic funnel of the wind tunnel (a); two diseased plants were placed in the main plexiglass tube (b); conidia exited the right plastic funnel through the overflow and nozzle orifices (c); and spores were trapped on the microscope tape attached to the rotating clock cylinder (plastic bottle, 24-h rotations) fixed to an electric timer (d). $\mathrm{mm}$ in length, $250 \mathrm{~mm}$ in diameter, approximately $3 \mathrm{~mm}$ in thickness of the Plexiglas), with cone-shaped ends (each 26 $\mathrm{cm}$ in length). The downwind end had an overflow orifice ( $29 \mathrm{~mm}$ in diameter). A narrow metal nozzle orifice ( 27 by $2 \mathrm{~mm}$ ) channeled the air flow toward a Melinex microscope tape (with a sticky substance made of $1 \mathrm{~g}$ of paraffin, $100 \mathrm{ml}$ of Toluene, and $9 \mathrm{~g}$ of clear Vaseline added to its surface) fastened to a 24-h rotating clock cylinder (approximately $3 \mathrm{~mm}$ of distance between the orifice and the tape). The cylinders were the lower parts of 1.5-liter plastic bottles (17 $\mathrm{cm}$ in length) fixed to the clock by a rubber ring $(5.2-\mathrm{cm}$ inner diameter) glued onto the bottom of the bottle.

Recording environmental conditions. Light intensity was recorded at the top of the lids of petri dishes or the double-room humidity boxes (described above) in detached-leaf experiments and at the level of plant height in the whole-plant experiments, with a Lambda LI-185B photometer (LI-COR Inc., Lincoln, NE) containing a quantum sensor. Light quality was recorded inside and outside of the petri dish or double-room humidity boxes and wind tunnel (described above) with a Spectra Wiz spectrometer Model EPP 2000 Fiberoptic (Stellarnet Inc., Tampa, FL). Temperature and $\mathrm{RH}$ were recorded inside the double-room humidity boxes, wind tunnels, growth chambers, and incubators with two-in-one sensors of SHT 75 (Sensirion AG., Staefa, Switzerland) with an accuracy of $\pm 0.3^{\circ} \mathrm{C}$ and $\pm 1.8 \% \mathrm{RH}$. Additionally, temperature and $\mathrm{RH}$ in growth chambers and in greenhouse compartments were recorded by a Priva greenhouse computer (Priva, De Lier, The Netherlands).

Germination of conidia. Three humidity boxes, each containing six detached leaflets, were placed in each of four growth chambers set to provide either 0-, $12-, 18-$, or $24-$ h day lengths. Shortly before lights were turned on, the leaflets were inoculated by touching them gently with source inoculum leaflets, with one inoculum leaflet for each of the healthy leaflets. Two leaflets from each humidity box (six leaflets from each treatment) were removed $24 \mathrm{~h}$ after inoculation and kept at $-2{ }^{\circ} \mathrm{C}$ (to stop the fungal growth) until further examination. These leaflets were then placed individually on microscope glass slides; a few droplets of $50 \%$ lactofuchsin were added to stain mycelium and conidia, followed by examination under a light microscope with bright field at a magnification of $\times 200$. Fifty conidia from each leaflet were assessed for germination. Conidia having a primary germ tube equal in length to at least half the width of the conidia were considered germinated. The experiments were repeated three times.

Production of conidia. Twelve humidity boxes, each containing seven leaflets of the same age, were inoculated by placing 
one drop $(15 \mu \mathrm{l})$ of a spore suspension on each leaflet. (The same method of inoculation was used in all experiments below with detached leaflets in humidity boxes). Immediately after inoculation, the humidity boxes were kept at $18 \mathrm{~h}$ of day length for the first 2 days to ensure uniform germination, and then they were transferred to $0,12,18$, and $24 \mathrm{~h}$ (three boxes at each day length). All together, six leaflets with conidia from each treatment were removed 9 days after inoculation and placed in 50$\mathrm{ml}$ centrifuge tubes, with $5 \mathrm{ml}$ of distilled water added, followed by hand shaking for $2 \mathrm{~min}$. The leaflets were removed from the centrifuge tube, and spores in drops of the resultant suspension were counted with a hemacytometer under a light microscope at $\times 200$. Two spore counts were done from each resultant suspension. The experiment was repeated three times. An experiment was set up where samples were kept for 4 days at $18 \mathrm{~h}$ before transferring to the different day lengths. Here, samples were kept for 5 days in the four day length chambers before assessing production of conidia (9 days after inoculation). The experiment was repeated three times, and all other procedures were as described above. Inoculated leaflets were also exposed to an 18-h day length for 4 days, followed by 5 days at 18, 20, 22, and $24 \mathrm{~h}$. All other procedures were as mentioned above, and the experiment was repeated three times.

Mistral pot roses were also grown in the greenhouse compartment as described above. Ten plants were spray inoculated with a 25-ml suspension of conidia made from 1-week-old source inoculum. Immediately after inoculation, the plants were moved to a growth chamber with $18 \mathrm{~h}$ of day length provided by mercury lamps at $200 \mu \mathrm{mol} \mathrm{m} \mathrm{m}^{-2} \mathrm{~s}^{-2}, 20^{\circ} \mathrm{C}$, and $80 \% \mathrm{RH}$ for 12 days. Four growth chambers were maintained with conditions as described in previous experiments, with $0-$, 12-, 18-, and 24-h day lengths. One wind tunnel was placed in each of the four growth chambers. Relative humidity of the intake air of the wind tunnels equaled that of the growth chambers, and was elevated by approximately $5 \%$ after passing through the canopy of the plant in the wind tunnel. Two diseased plants (inoculated 12 days before start of the experiments) were placed in each wind tunnel and, $1 \mathrm{~h}$ afterward, the air flow was switched on and maintained for 7 days (wind speed of approximately $0.06 \mathrm{~m} \mathrm{~s}^{-1}$ in the Plexiglas tubes and $2.9 \mathrm{~m} \mathrm{~s}^{-2}$ at the nozzle openings). A portable air-velocity meter (Model 1650; TSI Inc., St. Paul, MN) was used to measure the air flow speed through the plants and nozzle opening of the wind tunnel.

The clock cylinder revolved seven times during the 7-day test before the Melinex tapes were removed and prepared for microscope reading. Lactofuchsin was used to stain the conidia. There were 144 transect readings ( $2 \mathrm{~mm}$ or $1 \mathrm{~h}$ apart) at $\times 200$ for each tape. Thus, the spores counted in these transects represented the pooled number of spores trapped at a particular hour of the day for the 7 days the trap was operated. The counts from these transects were further pooled within eight 3-h periods (i.e., 0 to $0300 \mathrm{~h}, 0300$ to $0600 \mathrm{~h}$, and 0600 to $0900 \mathrm{~h}$ ) and the factors of day length, experimental repeat, and time period were included in the data analysis. The experiment was repeated three times and, before each repeat, the tunnels were cleaned with moist paper followed by $12 \mathrm{~h}$ of air flow to ensure that conidia were not inside the tunnel.

A similar experiment was set up with 18-, 20-, 22-, and 24-h day lengths (repeated twice). To clarify if there was a possible adaptation of the fungus and plant to the 18-h day length given prior exposure to the different day lengths that would influence the observed trends, inoculated plants were kept at the 12-h day length for 12 days followed by the various day-length exposures for $0,12,18$, and $24 \mathrm{~h}$ (experiment repeated four times).

Influence of day length on severity of powdery mildew. On each of 12 mildewfree uniformly aged pot roses of Mistral, three newly unfolded leaves were marked. The sulfur evaporator was shut off 2 days before inoculation. The plants were then spray inoculated as before with $2.5 \mathrm{ml}$ of conidial suspension per plant, and three plants (each considered as repeats/blocks) were placed at each of $0-, 12-, 18-$, or $24-\mathrm{h}$ day lengths. Eight days after inoculation, the three marked leaves from each plant (nine leaves from each treatment) were detached, and severity of the disease (percent area of leaf surface diseased) was assessed for each leaf, based on an assessment key for powdery mildew in roses (21).

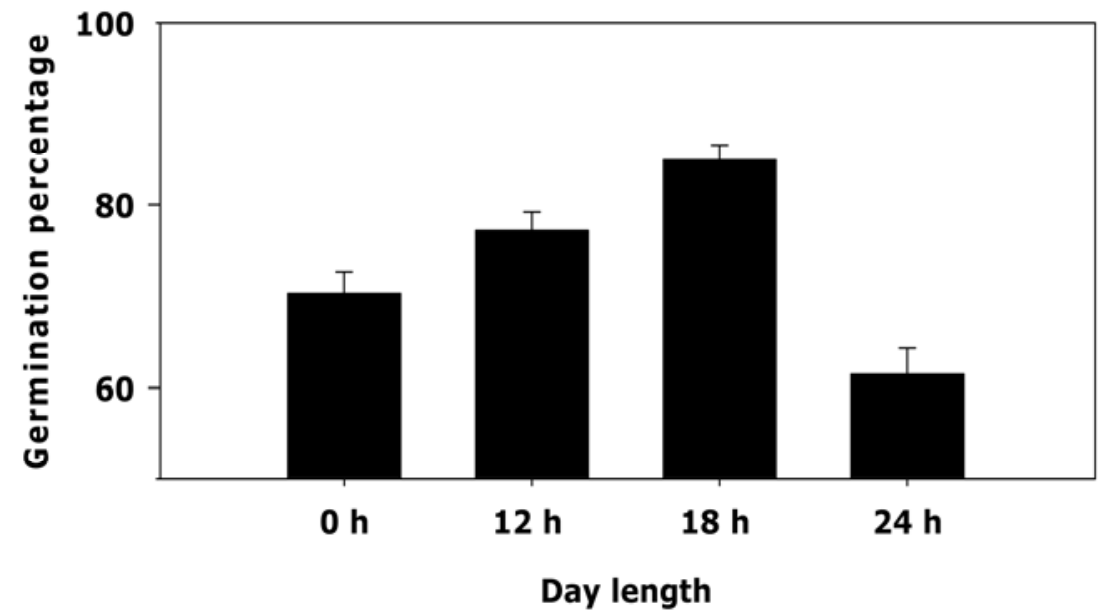

Fig. 2. Effect of day length on germination of Podosphaera pannosa conidia on detached leaflets of Rosa $\times$ hybrida cv. Mistral placed in double-room humidity boxes (photon flux density of light at 50 $\mu \mathrm{mol} \mathrm{m} \mathrm{m}^{-2} \mathrm{~s}^{-2}$ with mercury lamps, $20^{\circ} \mathrm{C}, 96 \pm 2 \%$ relative humidity). Assessments were made $24 \mathrm{~h}$ after inoculation. Each bar represents the mean of six randomly sampled leaflets in each of three replicated trials; bars indicate standard error of the mean.
Statistical analysis. Treatment effects were determined using Minitab version 14 for analysis of variance (GLM procedure) and mean comparison (Bonferroni test) at $P=0.05$.

Germination of conidia, production of conidia on detached leaflets. The mean percentages of germinated conidia were $70.3,77.2,84.9$, and 61.4 after exposure to 0-, 12-, 18-, and 24-h day lengths, respectively (Fig. 2), with a significant difference between 0 and $18 \mathrm{~h}$, and 24 and $18 \mathrm{~h}(P<$ $0.001)$.

Significantly more conidia were produced on detached leaflets exposed to 18-h day length compared with all other day lengths or continuous darkness (Fig. 3). When pretreated for 2 days in $18 \mathrm{~h}$ of light, there were also significant differences in numbers of conidia produced between 12 and $18 \mathrm{~h}$, and also between 24 and $18 \mathrm{~h}$ (Fig. 3A). The number of conidia produced under an 18-h day length was $1 \times 10^{4}$ co$\mathrm{nidia} / \mathrm{ml}$ and it was $1.6 \times 10^{3}$ and $5.2 \times 10^{3}$ for continuous darkness and continuous lighting, respectively. The 0 -h day length treatments (continuous dark) always produced much fewer conidia than the others; however, it was not significantly different from the 24-h day length treatment when exposed to pretreatment of $18 \mathrm{~h}$ for 2 days. Four days at 18-h day lengths prior to exposure to the different day lengths showed the same tendency, with less spore production at 12 and $24 \mathrm{~h}$ than at $18 \mathrm{~h}$, and there were no significant differences noticed between 12 and $18 \mathrm{~h}$ (Fig. 3B). $P$ values were $<0.001$ for the $F$ test in the two experiments. When comparing day lengths from 18 to $24 \mathrm{~h}$, there was a significant and steep drop in sporulation between 18 and $20 \mathrm{~h}$ (Fig. 3C). There were no differences in spore formation between exposures to 20,22 , and $24 \mathrm{~h}(P<0.001)$.

\section{RESULTS}


Spore production and release from whole plants in wind tunnels. Exposure of mildewed plants to various day lengths in the wind tunnels strongly affected the total number of conidia trapped (Fig. 4). In the experiment, where the incubation (after inoculation) took place at $18 \mathrm{~h}$ of day length for 12 days, the number of conidia trapped under $18 \mathrm{~h}$ of day length during 1 week was 24,903 . It was $101,4,691$, and 5,506 for continuous darkness, 12-h day length, and continuous lighting, respectively (Fig. 4A). When inoculated plants were incubated at a 12-h day length for 12 days, treatments of 0,12 , and $24 \mathrm{~h}$ significantly reduced the relative spore numbers to $0.8,44.9$, and $38.5 \%$, respectively (Fig. 4B). In both experiments (with either 18 or $12 \mathrm{~h}$ of day length during incubation), the number of conidia trapped under the 18-h day-length treatment was significantly greater from other day-length treatments $(P<0.001$ for the two experiments). Infected leaves exposed to complete darkness (0-h day length) in the wind tunnel also released significantly fewer spores compared with day lengths of 24 and $12 \mathrm{~h}$.

Day lengths of 20, 22, and $24 \mathrm{~h}$ reduced the relative spore numbers to $28.3,50.9$, and $42.9 \%$, respectively, relative to $18 \mathrm{~h}$ of day length (Fig. 4C). There was a significant reduction between 18 and $20 \mathrm{~h}(P<$ $0.001)$ but no significant differences between 20, 22, and $24 \mathrm{~h}$.

Disease severity on whole plants. The highest disease severity was recorded on plants exposed to an 18-h day length (70\%), followed by 12-h (48.3\%), 24-h (22.6\%), and 0-h (1.5\%) day lengths (Fig. $5)$. All treatments were significantly different from each other $(P<0.001)$. Significant interaction between treatment and

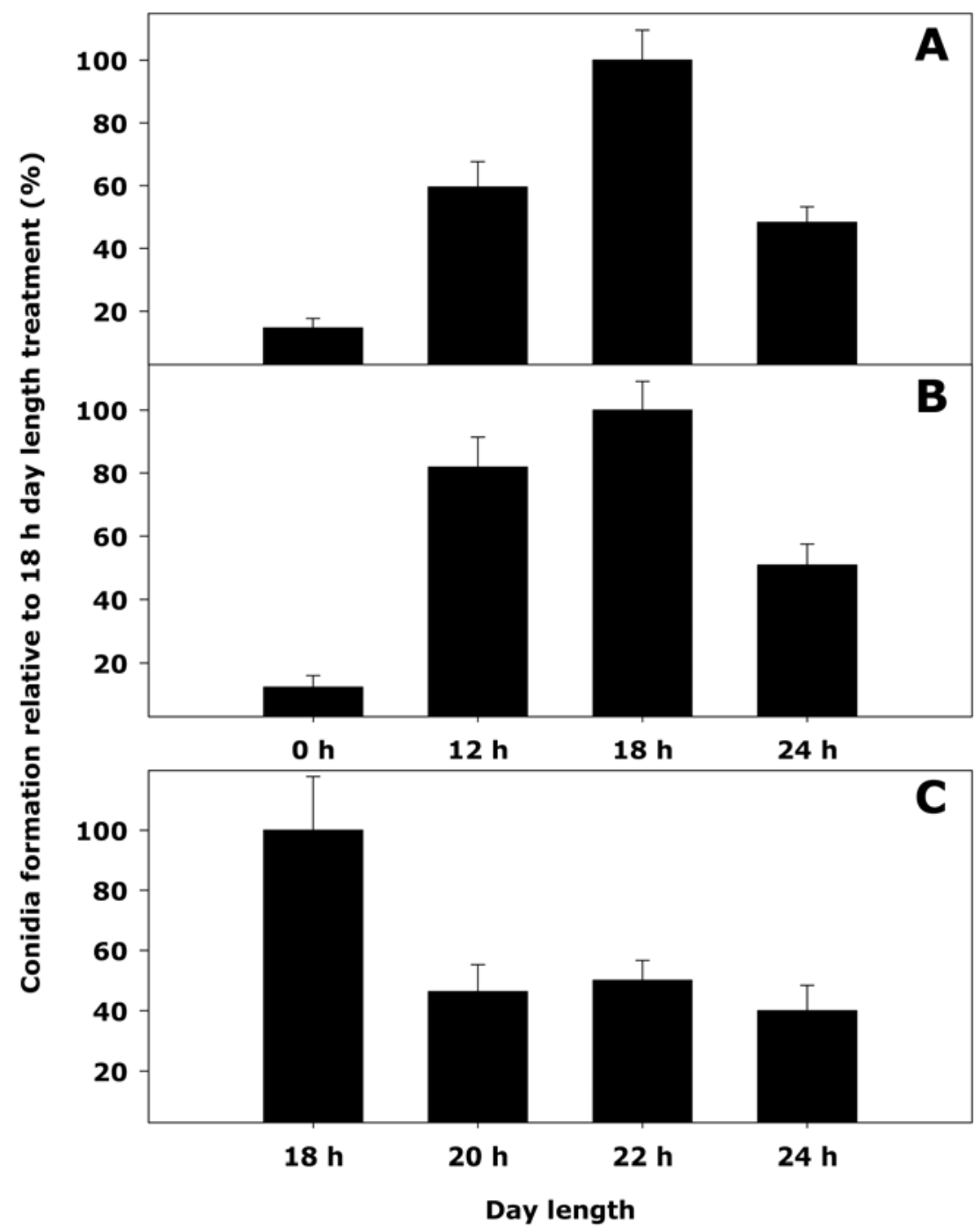

Fig. 3. Effect of day length on formation of Podosphaera pannosa conidia on detached leaflets of Rosa $\times$ hybrida cv. Mistral placed in double-room humidity boxes (photon flux density of light at $50 \mu \mathrm{mol}$ $\mathrm{m}^{-2} \mathrm{~s}^{-2}$ with mercury lamps, $20^{\circ} \mathrm{C}, 96 \pm 2 \%$ relative humidity). The boxes containing detached leaflets were kept at an 18-h day length for either $\mathbf{A}, 2$ or $\mathbf{B}$ and $\mathbf{C}, 4$ days after inoculation, and then transferred to the different day lengths. Samples were assessed 9 days after inoculation. Spore formation at the 18-h day length was set to $100 \%$, and all other treatments are relative to that. Data presented are an average of six spore counts in hemocytometer (two counts per treatment per replicate). Experiments were repeated three times. Bars indicate standard error of the mean. replicate (each plant within treatment considered as replicate) were noticed $(P=$ $0.01)$.

\section{DISCUSSION}

Our results clearly showed that day lengths of 20 to $24 \mathrm{~h}$ strongly suppressed powdery mildew development in roses and confirm what was earlier observed in greenhouse production of pot roses and cut roses $(17,20)$. Furthermore, we have demonstrated that the treatment effects involved a reduction in the quantity of spores produced on mildew colonies exposed to illumination for 20 to $24 \mathrm{~h}$ per day, as well as reduced germination potential of conidia. Productivity of roses increases with day length and is maximized by continuous lighting $(14,20)$. However, roses grown in continuous lighting with constant RH frequently exhibit stomatal malfunctioning (19), which reduces the keeping quality of roses due to severe water loss. Postharvest keeping quality of roses (vase life) was improved by reducing the day length to less than $24 \mathrm{~h}$ (H. R. Gislerød., unpublished data; 13). There was no additional suppression of powdery mildew when day length was increased from 20 to $24 \mathrm{~h}$, indicating that a day length of 20 to $22 \mathrm{~h}$ would be sufficient to obtain most of the suppressive effect upon powdery mildew while avoiding the potentially deleterious effects on keeping quality.

When preparing plants for exposure to different day lengths in the wind tunnels, we kept them at either 18- or 12-h day lengths for 12 days after inoculation. If comparing the resulting spore counts after exposure to different day lengths following the 12 days of incubation time at either 18 or $12 \mathrm{~h}$, the results were similar. This indicates that the high productivity of conidia and disease development at $18 \mathrm{~h}$ was not due to the environmental adaptation of plant and pathogen.

Our results might appear to contradict an earlier study (1) in which conidia of $P$. pannosa were not released at high $\mathrm{RH}$ (100\%) but were released when RH was reduced independent of light or darkness (1), thereby indicating that change in $\mathrm{RH}$ and not light is the principle factor in liberation of conidia. However, in our experiments, $\mathrm{RH}$ was maintained at $80 \pm 4 \%$. Thus, fluctuations in RH were minimal and not directly comparable with treatments imposed in the foregoing study (1). $P$. pannosa forms conidia in chains, and release of conidia is dependent upon maturation of new conidia from the base of the chain. We found that no or few mature conidia were produced if detached leaves or whole plants were kept in darkness.

Adams et al. (1) suggested that liberation of conidia of $P$. pannosa involved an active release mechanism (1). However, others have proposed a passive process for $P$. pannosa (6), as well as for Erysiphe graminis in wheat $(7,8)$, wherein conidial 
release required minimum wind speeds of 0.6 to $2 \mathrm{~m} \mathrm{~s}^{-1}$. In the present experiments, the wind speed in the canopy of the plants placed in the wind tunnels was not more than $0.06 \mathrm{~m} \mathrm{~s}^{-1}$ when passing through the plant canopy (i.e., one order of magnitude lower than the minimum wind speed previously reported to be necessary to release conidia). This supported the hypothesis that, if an active mechanism existed, discharge should occur in still air in response to environmental factors that trigger spore release (1).

There was a clear and significant reduction in percent germinated conidia when day length was increased from 18 to $24 \mathrm{~h}$. However, the reduction was not of the magnitude observed for total spore production. Similar to reports for $P$. aphanis (syn. Sphaerotheca macularis; 18), the cause of strawberry powdery mildew, we found no significant reduction of conidial germination at shorter day lengths or in light or in darkness.

Fungi causing powdery mildew are obligate biotrophic pathogens, and it is difficult to distinguish between a direct effect of day length on powdery mildew or an effect of day length on physiological processes in the plant that subsequently affect the fungus. Experiments conducted in oat powdery mildew showed that length of day during the growth of the plant prior to inoculation was an important factor in determining the level of resistance. Plants grown in $16 \mathrm{~h}$ of day length showed higher level of adult (ontogenic) plant resistance compared with plants grown in $8 \mathrm{~h}$ of day length (9), and it was speculated that presence of light during the initial infection induces the host plant resistance. For barley powdery mildew (E. graminis hordei), nascent colonies formed significantly more haustoria at $12 \mathrm{~h}$ post inoculation in darkness than in light (5).

Increasing day length will increase photoassimilation in greenhouse-grown roses (20). In certain plant tissues, susceptibility to powdery mildew appears to be dependent on availability of excess carbohydrates that facilitates disease development (23). Thus, rose plants treated with continuous lighting may have a higher nutrient supply for fungal growth and development compared with the other treatments. It may then be postulated that plants treated with continuous lighting should develop more powdery mildew than at shorter day lengths. Our results gave the opposite result.

There is a constant pressure on the greenhouse industry to reduce pesticide usage. From our results and previous findings in Norway $(17,20)$, we can now recommend increased day length as an important control measure to decrease powdery mildew in roses. This practice is currently being implemented among Norwegian rose growers. Furthermore, we have also found evidence that not only day length but also

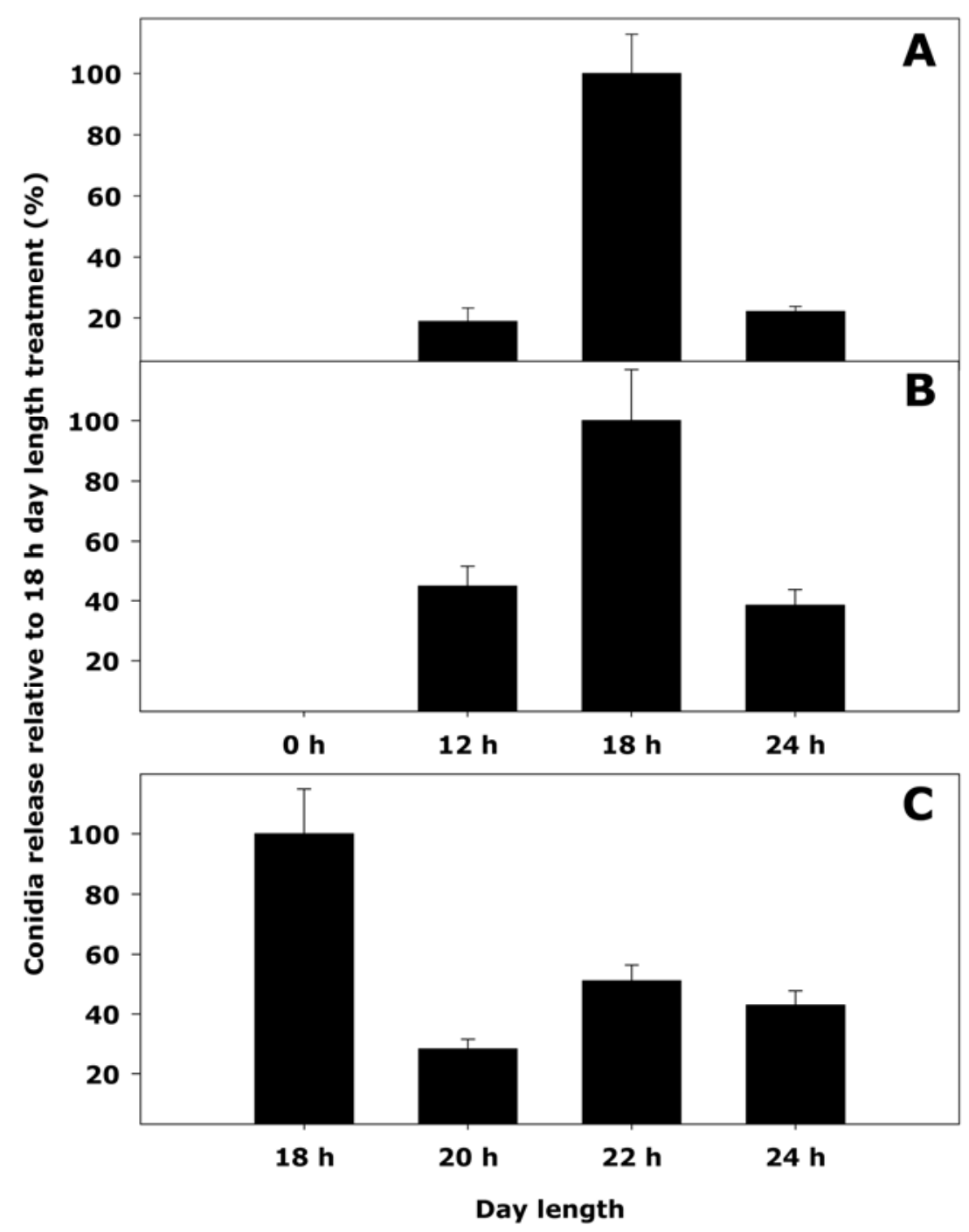

Fig. 4. Effect of day length on formation and release of Podosphaera pannosa conidia in whole plants of Rosa $\times$ hybrida cv. Mistral placed in a wind tunnel (photon flux density of light at $50 \mu \mathrm{mol} \mathrm{m} \mathrm{m}^{-2} \mathrm{~s}^{-2}$ with mercury lamps, $20^{\circ} \mathrm{C}, 80 \pm 4 \%$ relative humidity). Host plants were spray inoculated and kept in either $\mathbf{A}$ and $\mathbf{C}, 18-\mathrm{h}$ or $\mathbf{B}, 12-\mathrm{h}$ day length for 12 days before the day-length treatments started. Values given are the percent conidia trapped on a microscope tape relative to the 18-h day length (set to $100 \%$ ) during 1 week. Experiments were repeated A, three; B, four; or $\mathbf{C}$, two times. Bars indicate standard error of the mean.

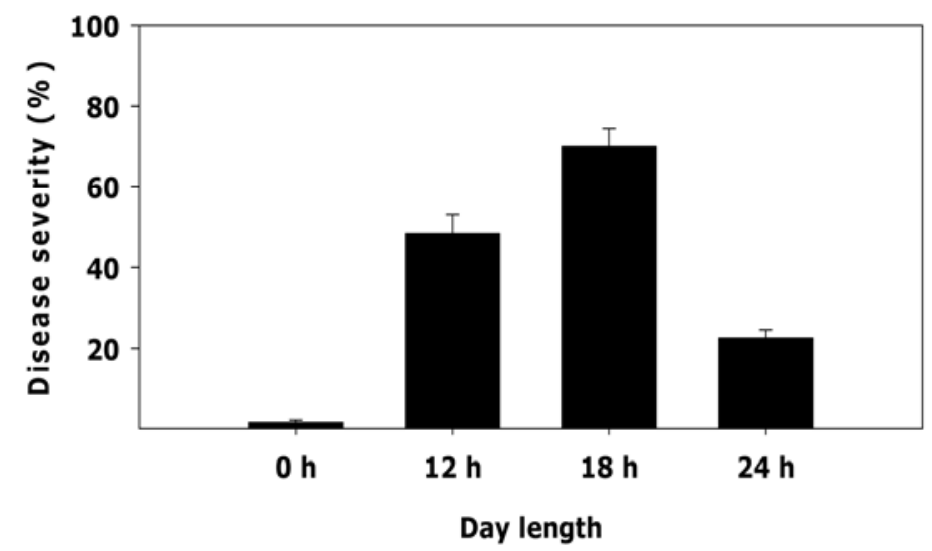

Fig. 5. Effect of day length on disease severity of powdery mildew caused by Podosphaera pannosa in whole plants of Rosa $\times$ hybrida cv. Mistral. Immediately after inoculation, plants were placed in growth chambers (photon flux density of light at $50 \mu \mathrm{mol} \mathrm{m} \mathrm{m}^{-2} \mathrm{~s}^{-2}$ with mercury lamps, $20^{\circ} \mathrm{C}, 80 \pm 4 \%$ relative humidity) with $0-, 12-, 18-$, or $24-$ h day lengths (three plants in each). Three leaves from each plants were detached 8 days after inoculation and percent diseased leaf area (severity) was scored based on visual comparison with an assessment key. Data presented are an average score of nine diseased leaves. Bars indicate standard error of the mean. 
light quality strongly influence powdery mildew, and very low light intensities seem necessary to suppress the fungus (A. Suthaparan, unpublished data). Lightemitting diode (LED) technology is currently developing rapidly, and, in the future, it may be possible to manipulate day lengths and light qualities with low-energy LED lamps with the purpose of controlling or delaying powdery mildew epidemics. Finally, this information may also be transferred to other greenhouse crops where powdery mildew is problematic, such as cucumber and tomato.

\section{ACKNOWLEDGMENTS}

This work was funded by the Norwegian Research Council. We thank the Norwegian rose growers' association for their valuable contribution and technicians at Centre for Plant Research (SKP) and Norwegian Institute for Agricultural and Environmental Research, Plant Health and Plant Protection Division.

\section{LITERATURE CITED}

1. Adams, G. C., Gottwald, T. R., and Leach, C. M. 1986. Environmental factors initiating liberation of conidia of powdery mildews. Phytopathology 76:1239-1245.

2. Ambra, R., Grimaldi, B., Zamboni, S., Filetici, P., Macino, G., and Ballario, P. 2004. Photomorphogenesis in the hypogeous fungus Tuber borchii: isolation and characterization of Tbwc-1 the homologue of the blue light photoreceptor of Neurospora crassa. Fungal Genet. Biol. 41:688-697.

3. Blumenstein, A., Veinken, K., Tasler, R. Purschwitz, J., Veith, D., Frankenberg-Dinkel, N., and Fischer, R. 2005. The Aspergillus nidulans phytochrome FphA represses sexual development in red light. Curr. Biol. 15:18331838.

4. Bredmose, N. 1993. Effect of year-round supplementary lighting on shoot development, flowering and quality of two glasshouse rose cultivars. Sci. Hortic. 54:69-85.

5. Edwards, H. H. 1993. Light affects the forma- tion and development of primary haustoria of Erysiphe graminis hordei in leaf epidermal cells of Hordeum vulgare. Physiol. Mol. Plant Pathol. 42:299-308.

6. Frinking, H. D. 1977. Research on wind dispersion of rose mildew spores (Sphaerotheca pannosa) in field, glasshouse and climate room. Grava 16:155-158.

7. Hammett, K. R. W., and Manners, J. G. 1973. Conidium liberation in Erysiphe graminis II. Conidial chain and pustule structure. Trans. Br. Mycol. Soc. 61:121-133.

8. Hammett, K. R. W., and Manners, J. G. 1974. Conidium liberation in Erysiphe graminis III. Wind tunnel studies. Trans. Br. Mycol. Soc. 62:267-282.

9. Jones, I. T. 1975. The preconditioning effect of day length and light intensity on adult plant resistance to powdery mildew in Oats. Ann. Appl. Biol. 80:301-309.

10. Linde, M., and Shishkoff, N. 2003. Powdery mildew. Pages 158-165 in: Encyclopedia of Rose Science. A. Roberts, T. Debener, and S. Gudin, eds. Elsevier Science, Oxford

11. Mastalerz, J. W. 1987. Environmental factors, light, temperature, carbon dioxide. Page 165 in: Roses Manual. R. W. Langhans, ed. Roses Inc. USA.

12. Moe, R., Grimstad, S. O., and Gislerod, H. R. 2006. The use of artificial light in year round production of greenhouse crops in Norway. Acta Hortic. 711:35-42.

13. Mortensen, L. M., and Fjeld, T. 1998. Effects of air humidity, lighting period and lamp type on growth and vase life of roses. Sci. Hortic. 73:229-237.

14. Mortensen, L. M., and Gislerød, H. R. 1999. Influence of air humidity and lighting period on growth, vase life and water relations of 14 rose cultivars. Sci. Hortic. 82:289-298.

15. Mortensen, L. M., and Gislerød, H. R.. 2005. Effect of air humidity variation on powdery mildew and keeping quality of cut roses. Sci. Hortic. 104:49-55.

16. Mortensen, L. M., Gislerod, H. R., and Mikkelsen, H. 1992. Effects of different levels of supplementary lighting on year round yield of cut roses. Gartenbauwissenschaft 57:198-202. (In Norwegian)

17. Mortensen, L. M., Pettersen, R. I., and
Gislerød, H. R. 2007. Air humidity variation and control of vase life and powdery mildew in cut roses under continuous lighting. Eur. J. Hortic. Sci. 72:255-259.

18. Peries, O. S. 1962. Studies on strawberry mildew caused by Sphaerotheca macularis (Wallr. ex Fries) Jaczewski I. Biology of the fungus. Ann. Appl. Biol. 50:211-224.

19. Pettersen, R. I., Moe, R., and Gislerød, H. R. 2007. Growth of pot roses and post-harvest rate of water loss as affected by air humidity and temperature variations during growth under continuous light. Sci. Hortic. 114:207-213.

20. Pettersen, R. I., Mortensen, L. M., Moe, R. and Gislerod, H. R. 2006. Air humidity control essential for rose production under continuous lighting. Acta Hortic. 711:323-331.

21. Price, T. V. 1970. Epidemiology and control of powdery mildew (Sphaerotheca pannosa) on roses. Ann. Appl. Biol. 65:231-248.

22. Rogers, G. S. 1959. Some effects of moisture and host plant susceptibility on the development of powdery mildew of roses, caused by Sphaerotheca pannosa var. rosae. Memoir Cornell Univ. Agric. Exp. Stn. 363:1-37.

23. Schoeman, M. H., Manicom, B. Q., and Wingfield, M. J. 1995. Epidemiology of powdery mildew on mango blossoms. Plant Dis. 79:524-528.

24. Sivapalan, A. 1993. Effects of water on germination of powdery mildew conidia. Mycol. Res. 97:71-76.

25. Stanhil, G., Fuchs, M., Bakker, J., and Moreshet, S. 1973. The radiation balance of a greenhouse crop. Agric. Meteorol. 11:385-404.

26. Suthaparan, A., Herrero, M. L., Pettersen, R. I., Torre, S., Stensvand, A., Gadoury, D. M. and Gislerod, H. R. 2008. Effects of day length on formation, release and germination of powdery mildew conidia in roses and severity of disease. (Abstr.) J. Plant Pathol. 90S:191.

27. Tan, Y., Merrow, M., and Roenneberg, T. 2004. Photoperiodism in Neurospora crassa. J. Biol. Rhythm. 19:135-143.

28. Yarwood, C. A. 1978. History and taxonomy of powdery mildews. Pages 1-37 in: The Powdery Mildew. D. M. Spencer, ed. Academic Press, London.

29. Yarwood, C. E. 1956. Obligate parasitism. Annu. Rev. Plant Physiol. 7:115-142. 